\title{
Corundum dissolution in concentrated sodium hydroxide solution
}

\author{
*Yu-sheng Wu ${ }^{1}$, Hong-liang Li ${ }^{1}$, Feng-ling Shi ${ }^{3}$, xiao-fu Liu ${ }^{1}$, Gui-qao Su ${ }^{2}$, and Yan-ping Qu ${ }^{1}$ \\ 1. School of Materials Science and Engineering, Shenyang University of Technology, Shenyang 110870, China \\ 2. Shenyang Research Institute of Foundry, Shenyang 110022, China \\ 3. Shenyang Liming Aero Engine (Group) Co. Ltd., Shenyang 110043, China
}

\begin{abstract}
The corundum ( $\alpha$-alumina) core has been considered as a suitable candidate for investment casting of hollow, high pressure turbine engine airfoils due to its excellent properties. However, the efficiency of removing alumina cores in concentrated caustic solution cannot meet the needs of industrial production. In this paper, the effects of temperature and initial solution concentration on dissolution of $\alpha$-alumina were studied by the classical weight-loss method. The fractal kinetic model was developed in order to describe $\alpha$-alumina dissolution, assuming that the nonporous particles shrank during reaction process. The results show that the dissolution rate increases with increasing reaction temperature and initial solution concentration. Especially, the initial solution concentration has a significant influence on $\alpha$-alumina dissolution rate at a higher reaction temperature. The activation energies decrease with increasing initial solution concentration, and the chemical reaction is the rate-controlling step.
\end{abstract}

Key words: kinetics; corundum; sodium hydroxide solution; dissolution; core

CLC numbers: TG221 ${ }^{+} 1 \quad$ Document code: A Article ID: 1672-6421(2016)06-422-05

$\mathrm{E}$ fforts to achieve high performance in turbine engines have been limited by the ceramic materials used in the investment casting of hollow, high pressure turbine engine airfoils. The process requirements for casting temperatures and soaking time are greater than $1,700{ }^{\circ} \mathrm{C}$ and 16 hours, respectively, exceeding the permissible ceramic/molten metal contact time limitation. Generally, the ceramic used for casting cores must be able to serve as the material for the casting mold in the investment casting of nickel based superalloy turbine airfoils (e. g. turbine blades and vanes) with internal air cooling passages.

Corundum ( $\alpha$-alumina) has been considered as a candidate for investment casting of hollow, high pressure turbine engine airfoils for its excellent properties, such as high chemical metallurgy stability and creep resistance, which can provide better dimensional tolerance in internal passages of airfoils ${ }^{[1-2]}$. However, it is very difficult to leach out the core made in $\alpha$-alumina from the casting. Many methods and apparatus have been employed with leaching solution of potassium

\section{*Yu-sheng Wu}

Male, born in 1978, Ph.D, Professor. His research interests focus mainly on the preparation and characterization of powder materials, and he has published over 40 academic papers

E-mail:wuyus@sut.edu.cn

Received: 2015-11-26; Accepted: 2016-07-18 hydroxide or sodium hydroxide (10-70 wt.\%) ${ }^{[3-5]}$. But the efficiency of removing alumina core in concentrated caustic solution cannot yet meet the needs of industrial production.

During the hydrometallurgical process, the actual production efficiency (i.e., bauxite leaching) is determined by chemical reaction rate rather than thermodynamic conditions. Therefore, it has a great practical significance to study the dissolution kinetics for identifying the main rate-controlling step and accelerating the dissolution process ${ }^{[6]}$. Many literatures were focused on the dissolution kinetics of corundum, gibbsite and diaspore using a relatively lower caustic concentration ${ }^{[7-15]}$. However, investigation on dissolution kinetics of corundum in high concentration caustic was not found up to date. The present research is focused on the dissolution behavior of $\alpha$-alumina in concentrated sodium hydroxide solution and on the fractal kinetic model of corundum dissolution. The aim is to provide theoretical support for optimizing the conditions of removing alumina core.

\section{Experimental procedure}

Fused corundum powder, purchased from the Dazhong No.7 Grinding Wheel., Ltd, China, was used as the raw material. The powder was mainly composed of $95.45 \%$ $\mathrm{Al}_{2} \mathrm{O}_{3}, 1.56 \% \mathrm{SiO}_{2}, 2.82 \% \mathrm{TiO}_{2}$, and $0.16 \% \mathrm{Fe}_{2} \mathrm{O}_{3}$. The 
sodium hydroxide was analytical grade and purchased from the National Pharmaceutical Group, China.

Sodium hydroxide solution was prepared by dissolving sodium hydroxide chips in exact amount of de-ionized water. For each experiment, $5 \mathrm{~g}$ corundum powder and $50 \mathrm{ml}$ sodium hydroxide solution were loaded into an $80 \mathrm{ml}$ high pressure reaction vessel. Then, the reaction vessel was put into an isothermal silicon oil bath with a mechanical stirrer. When the reaction ended, the reaction vessel was quickly cooled to room temperature by water. The reaction temperature and initial solution concentration varied from 160 to $220{ }^{\circ} \mathrm{C}$ and $50 \mathrm{wt} . \%$ to $65 \mathrm{wt} . \%$, respectively. The undissolved corundum powders were centrifuged, washed, dried, and weighed. After each run, the dissolution rate of corundum was calculated by the classical weight-loss method as followed:

$$
\mathrm{x}=\frac{5-\mathrm{m}}{5} \times 100 \%
$$

where $x$ is dissolution rate of corundum and $m$ is weight of undissolved corundum.

The weight of corundum powder was measured by Mettler M3 microbalance, with a precision of $0.2 \mu \mathrm{g}$. The morphology of the sample (i.e., corundum powder) was studied with a Field Emission Scanning Electron Microscope (SEM, SU8010) operated at an accelerating voltage of $20.0 \mathrm{kV}$. Structural phase analysis of the sample (i.e., corundum powder) was performed by an XRD-7000 equipped with $\mathrm{Cu} K_{\alpha}$ radiation. A continuous mode was used to collect $2 \theta$ data from $10^{\circ}$ to $70^{\circ}$ with a sampling pitch of $0.02^{\circ} \cdot \mathrm{s}^{-1}$.

\section{Results and discussion}

\subsection{SEM examination of corundum powder}

Figure 1 shows the SEM micrographs of the corundum powder. It can be seen that the particles are in irregular shapes including prismoidal, blocky and cubic morphologies.
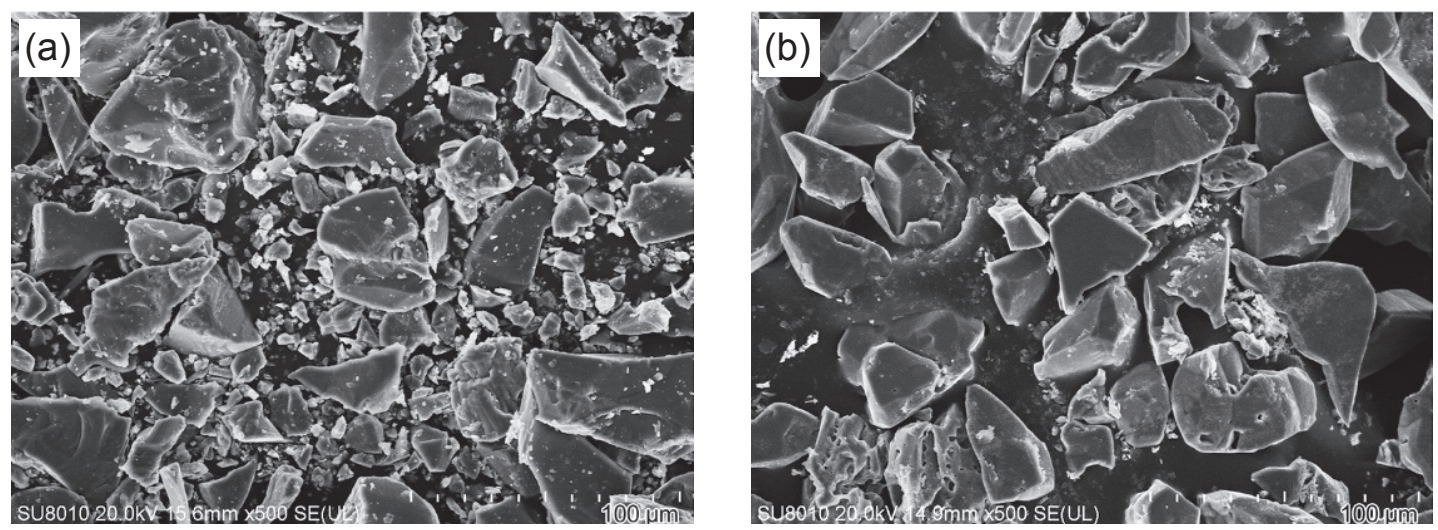

Fig. 1: SEM photographs: (a) corundum; (b) incompletely dissolved corundum

\subsection{Effects of reaction temperature and concentration of sodium hydroxide solution on dissolution rate of corundum}

The effects of reaction temperature and concentration of sodium hydroxide solution on dissolution rate of corundum are shown in Fig. 2. It is found that the correlation curves under different temperatures or concentrations are relatively similar. However, the increasing value in dissolution rate has a significant difference in different temperature ranges. With $60 \mathrm{wt} . \%$ sodium hydroxide solution and reaction time of $6 \mathrm{~h}$, when the temperature increases from 180 to $200{ }^{\circ} \mathrm{C}$, the dissolution rates increases $12.5 \%$, while as the reaction temperature increases from 200 to $220{ }^{\circ} \mathrm{C}$, the dissolution rate increases $46 \%$. This indicates that higher temperature can enhance corundum dissolution, and the chemical reaction should be the main rate-controlling step, the detailed discussions of which are given in section 2.3.

In order to ascertain the effect of sodium hydroxide concentration on dissolution of corundum, the variations of corundum dissolution rate with time at $220^{\circ} \mathrm{C}$ are plotted in Fig. 3. Similar to temperature, sodium hydroxide concentration has a
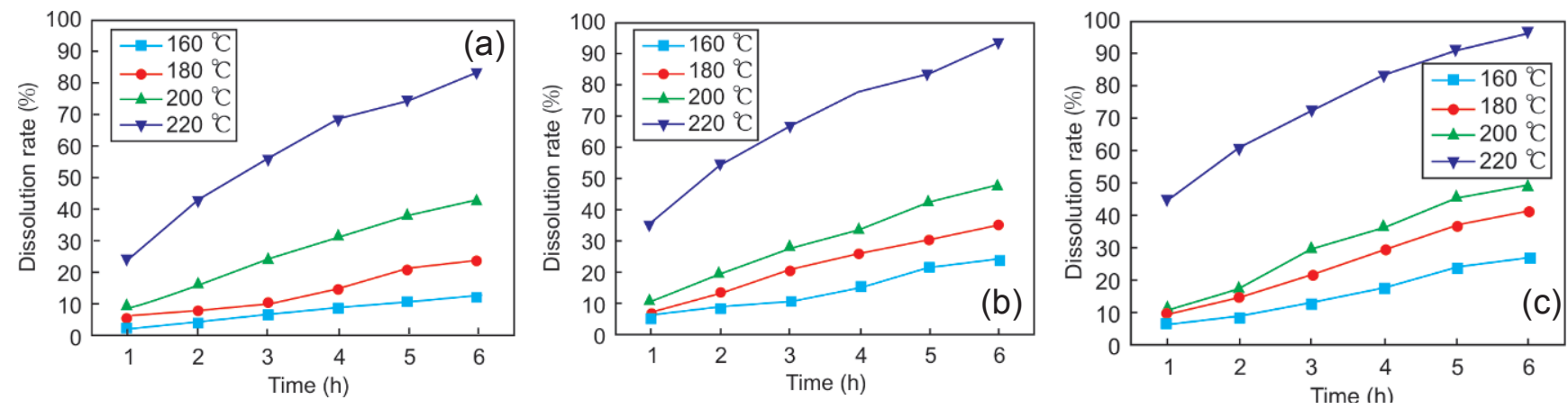

Fig. 2: Dissolution rate of corundum at different temperatures and concentration: (a) $50 \mathrm{wt} . \%$ sodium hydroxide; (b) $60 \mathrm{wt} . \%$ sodium hydroxide; (c) $65 \mathrm{wt}$ \% sodium hydroxide 

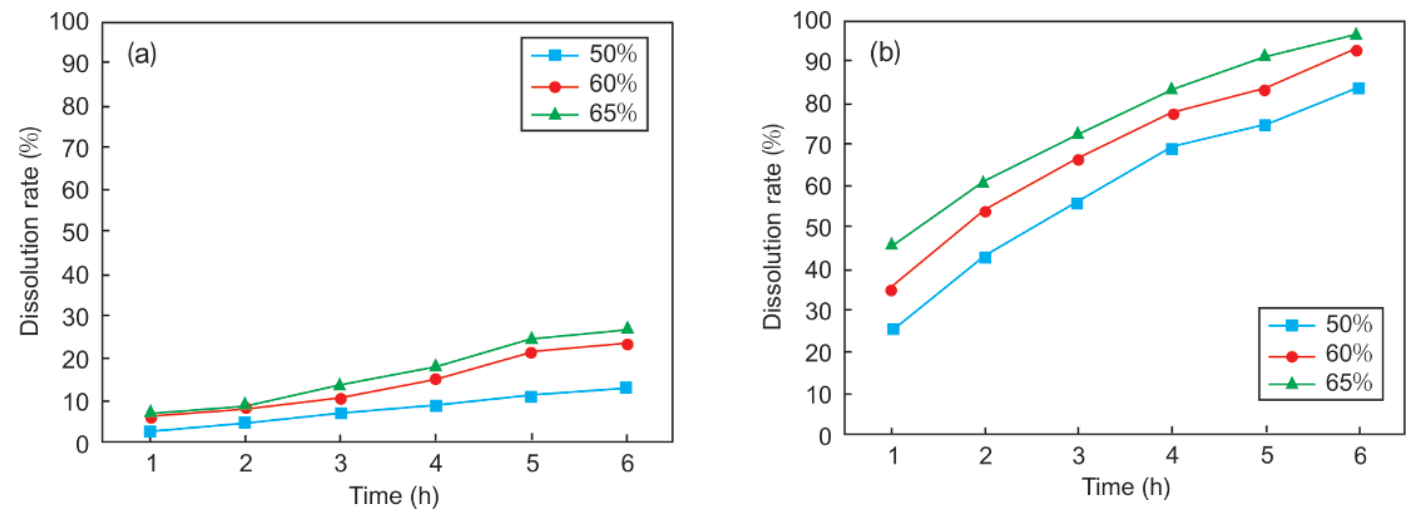

Fig. 3: Dissolution rate of corundum: (a) at $160{ }^{\circ} \mathrm{C}$; (b) at $220^{\circ} \mathrm{C}$

significant impact on corundum dissolution rate, but the change rate is relatively smaller. It is further found from Figs. 2 and 3 that the initial solution concentration influences the $\alpha$-alumina dissolution significantly at higher reaction temperatures.

\subsection{Dissolution kinetics analysis}

Generally, the leaching process of mineral may have three kinds of cases ${ }^{[16]}$. Firstly, the resulting product is soluble in solution and the size of solid particles decreases during the reaction process. Therefore, the reaction kinetics can be determined according to the shrinking core model. Secondly, resulting products adhere to the unreacted core which can also be described by the shrinking core model. Finally, solid reactants diffuse in the reaction mass. The liquid phase may diffuse into the ore through the channels, so that leaching reaction occurs inside and outside the ore. The reaction of sodium hydroxide with corundum does not produce solid-phase in dissolution process, so it belongs to the first case, or the shrinking core mode.

Assuming that the corundum is a spherical particle with homogeneous size and the change of surface activity and sodium hydroxide concentration during dissolution is ignored. Then the dissolution reaction kinetics can be determined according to the shrinking core model. In this process, the reaction is controlled by diffusion as well as the chemistry reaction. Therefore, the dissolution kinetics for a well-mixed batch-wise system of constant volume can be expressed as Eq. (2) or Eq. (3) ${ }^{[6]}$.

$$
\begin{aligned}
1-(1-x)^{\frac{1}{3}} & =\frac{k_{r} C_{A 0}^{n}}{\rho r_{\mathrm{p} 0}} t \\
1-(1-x)^{\frac{1}{3}} & =\frac{k_{r} C_{A 0}}{\rho r_{\mathrm{p} 0}} t
\end{aligned}
$$

where $x$ is the dissolution rate of corundum, $k_{r}$ is the rate constant of reaction, $C_{A 0}$ is the initial concentration of sodium hydroxide, $n$ is the reaction order, $\rho$ is the density of corundum, $r_{p 0}$ is the particle diameter size, and $t$ is the reaction time.

Considering the influence of particle shape on the entire surface area of particles, a fractal kinetic model was developed as followed:

$$
1-(1-x)^{\frac{1}{F_{p}}}=\frac{k_{r} C_{A 0}^{n}}{\rho r_{\mathrm{p} 0}} t
$$

where $F_{p}$ is the shape factor of solid particle. The value of $F_{p}$

$$
1-(1-x)^{\frac{1}{F_{p}}}=\frac{k_{r} C_{A 0}}{\rho r_{\mathrm{p} 0}} t
$$

varies with the shape (i.e. infinite flat-like $=1$, column-like $=$ 2 , and cube or ball-like $=3$ ). The particle morphology of the corundum used in the test is between the cylinder and the cube. Using software Matlab2010a, all constants with 0.1 intervals between 2 and 3 as the shape factor were put into the Eq. (4) and Eq. (5). The shape factor 2.5 of solid particle was determined through Least squares linear regression ${ }^{[6,8]}$. Therefore, the dissolution kinetics can be re-written to Eq. (6) and Eq. (7).

where Eq. (6) is applicable to chemically reaction controlled

$$
\begin{aligned}
& 1-(1-x)^{\frac{1}{2.5}}=\frac{k_{r} C_{A 0}^{n}}{\rho r_{\mathrm{p} 0}} t \\
& 1-(1-x)^{\frac{1}{2.5}}=\frac{k_{r} C_{A 0}}{\rho r_{\mathrm{p} 0}} t
\end{aligned}
$$

kinetics and Eq. (7) refers to diffusion controlled kinetics. The main control step cannot be determined by fitting the kinetic model because the left of Eq. (6) and Eq. (7) have the same expressions. It is feasible to determine the main control step of dissolution process by calculating the activation energy. Eq. (6) and Eq. (7) can be written as a unified semi-empirical model as follows:

$$
1-(1-x)^{\frac{1}{2.5}}=K t
$$

where $K$ is the overall rate constant of reaction.

In order to reveal the rate-controlling step of the dissolution process, the dissolution rates of corundum at various reaction temperatures and sodium hydroxide concentrations are plotted in Fig. 4. According to Fig. 4, when the data of corundum dissolution rate process are processed by the shrinking core model, all the controlling-model-based characteristic functions versus leaching time give a good linear relationship. This indicates corundum dissolution agrees with the kinetic model of shrinking core.

The apparent reaction rate constant $\mathrm{K}$ can be determined by the slope of the curves. Based on the apparent reaction rate constant measured at different temperatures, the apparent reaction energy of activation in different concentrations can be calculated according to the Arrhenius formula (9) ${ }^{[17-18]}$ 

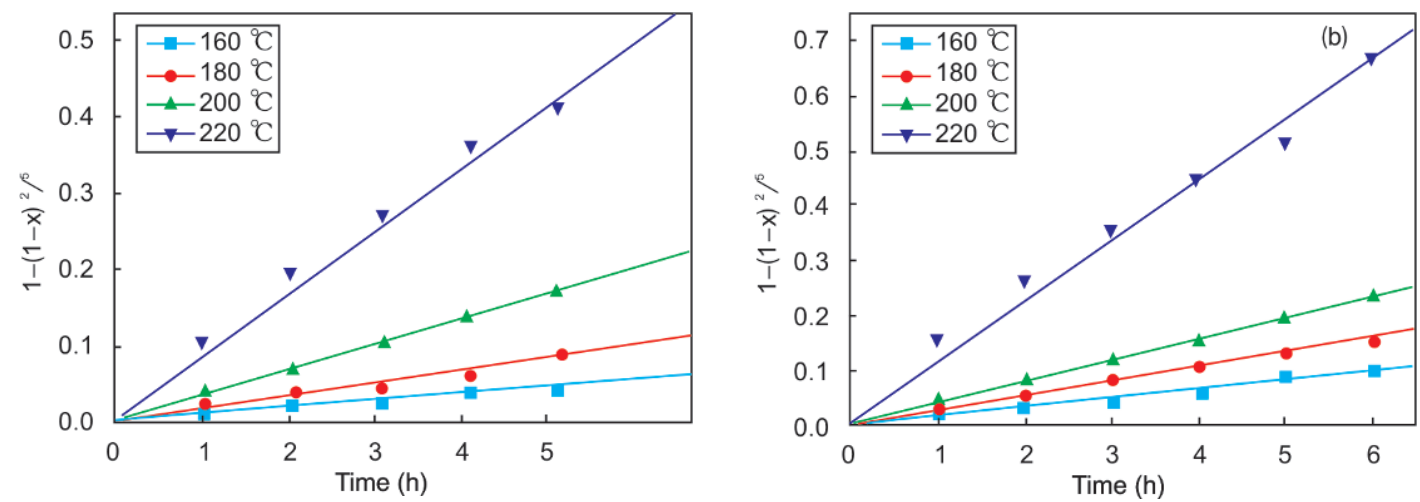

Fig. 4: Relationship of characteristic functions and durations in different concentrations: (a) 50 wt. $\%$ sodium hydroxide; (b) 60 wt. \% sodium hydroxide; (c) 65 wt. \% sodium hydroxide

$$
K=k_{0} \exp \left(-\frac{E_{a}}{R T}\right)
$$

where, $k_{0}$ is the pre-exponential factor, $E_{a}$ is the apparent activation energy, $\mathrm{J} \cdot \mathrm{mol}^{-1}, R$ is the molar gas constant, which is equal to $8.314 \mathrm{~J} \cdot \mathrm{mol}^{-1} \cdot \mathrm{K}^{-1}, \mathrm{~T}$ is the thermodynamic temperature. For the convenience of calculation, Formula (9) is converted to natural logarithm form as follow:

$$
\ln K=-\frac{E_{a}}{R T}+\ln k_{0}
$$

The plots of reaction rate constant versus different temperatures in different concentration solutions are shown in Fig. 5. From the slopes of curves, it can be evaluated that the apparent activation energies of sodium hydroxide concentration at 50wt.\%, 60wt.\% and $65 \mathrm{wt} . \%$ are $66.48 \mathrm{KJ} \cdot \mathrm{mol}^{-1}, 52.79 \mathrm{KJ} \cdot \mathrm{mol}^{-1}$ and $51.38 \mathrm{KJ} \cdot \mathrm{mol}^{-1}$, respectively. The result proves that the solution concentration has little impact on reaction mechanism. Furthermore, it can be concluded that the chemical reaction is the rate-controlling step in the dissolution process ${ }^{[6,18]}$. In addition, the dissolution kinetics can be expressed by Eq. (6).
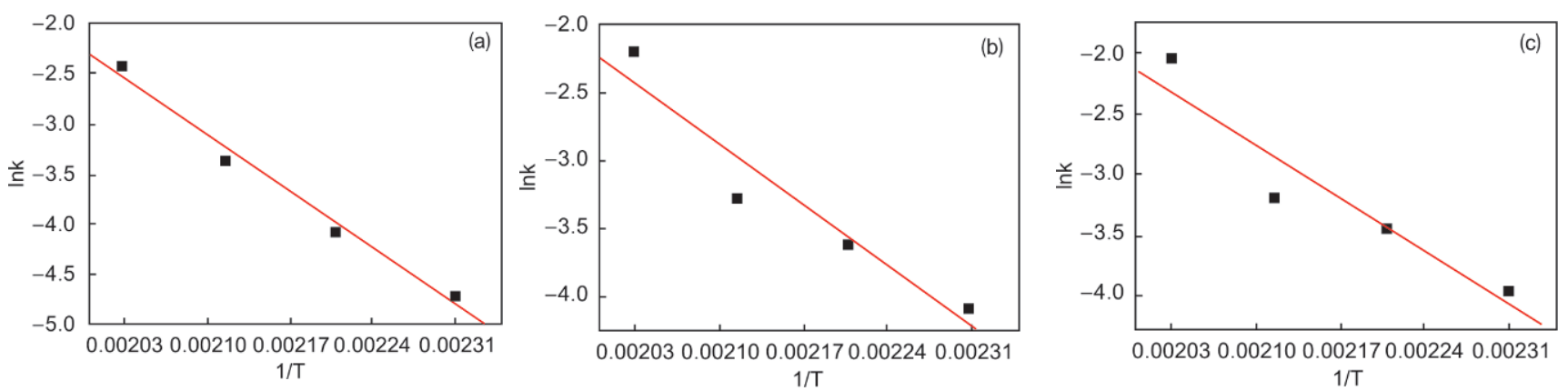

Fig. 5: Relationship between $K$ and temperature in dissolution process: (a) 50wt.\% sodium hydroxide; (b) 60 wt. $\%$ sodium hydroxide; (c) $65 \mathrm{wt} . \%$ sodium hydroxide

\subsection{Dissolution mechanism}

Fused corundum has a perfect crystalline structure. It consists of corundum (marked as \&) and mullite (marked as \#), and mullite is the major phase in crystal. The following reactions may occur during the dissolution process:

$$
\begin{gathered}
\mathrm{Al}_{2} \mathrm{O}_{3}+2 \mathrm{NaOH}+3 \mathrm{H}_{2} \mathrm{O}+a q \rightleftharpoons 2 \mathrm{NaAl}(\mathrm{OH})_{4}+a q \\
\mathrm{SiO}_{2}+2 \mathrm{NaOH}+a q \rightleftharpoons \mathrm{Na}_{2} \mathrm{SiO}_{3}+\mathrm{H}_{2} \mathrm{O}+a q
\end{gathered}
$$

The whole process can be divided into four steps. Firstly, the surface of corundum particles is wetted by sodium hydroxide liquor; then, alumina and silica react with $\mathrm{OH}^{-}$; in the third step, diffusion layers of $\mathrm{NaAl}(\mathrm{OH})_{4}$ and $\mathrm{Na}_{2} \mathrm{SiO}_{3}$ cover the corundum particle; and finally, the $\mathrm{Al}(\mathrm{OH})_{4}^{-1}$ and $\mathrm{SiO}_{3}{ }^{-2}$ diffuse out from the diffusion layer into the liquid, while $\mathrm{OH}^{-}$diffuses from solution to the contact interface of the solid phase. The second step (chemical reaction) and the fourth step (diffusion) dominate the whole reaction process under certain conditions. Based on above analysis, the apparent activation energy for the reaction of fused corundum and sodium hydroxide solution is greater than $51.38 \mathrm{KJ} \cdot \mathrm{mol}^{-1}$, indicating that the chemical reaction is the ratecontrolling step.

Dissolution of crystalline materials is a lattice damage process. During dissolution, the lattice damage of fused corundum is attributed to the incorporation of $\mathrm{OH}^{-}$ions into the crystal lattice. Thus, the solubility is determined by the activity of $\mathrm{OH}^{-}$ions in lattice. Corundum belongs to the trigonal system. Ionic bond transit to covalently, the oxygen ions have hexagonal closest packing with much smaller particle spacing, resulting in solid structure and good chemical stability. The mullite is orthorhombic with structural imbalances in the presence of oxygen and more susceptible to be decomposed by sodium oxide or potassium oxide (which can be verified from Fig. 6). Peak intensity of mullite is conspicuously reduced after dissolution, indicating that most of mullite has been dissolved already. 


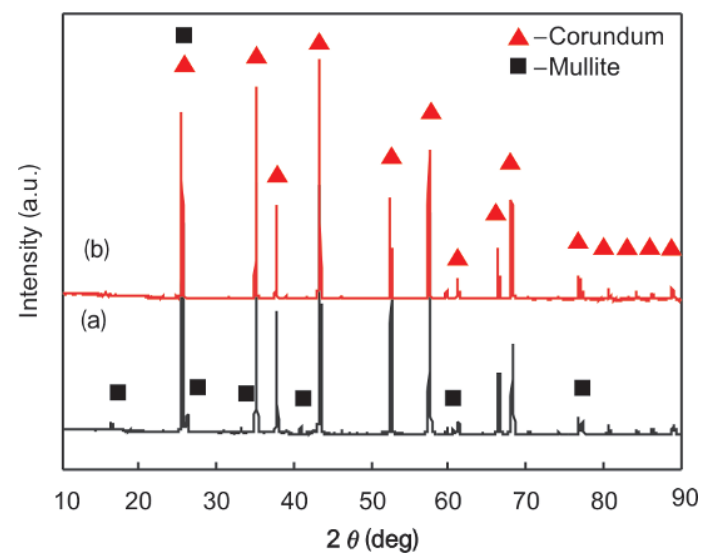

Fig. 6: XRD patterns of (a) corundum; (b) partly dissolved corundum

Fig. 1 (b) is the scanning electron micrograph of undissolved corundum obtained from the $60 \mathrm{wt} . \%$ sodium hydroxide solution at $200{ }^{\circ} \mathrm{C}$ for $6 \mathrm{~h}$. It can be seen from Fig. 1(b) that the particle size distribution of residue is quite different from the raw materials. Most of small particles disappeared, and coarse particles became smaller and smoother. The difference of particle shape is not obvious between raw materials and partly dissolved particles. Therefore, it can be concluded that the dissolution process of corundum particles begins from the surface and then to dissolve corrosion.

\section{Conclusions}

(1) The dissolution kinetics of corundum in concentrated sodium hydroxide solution was studied in an isothermal batch reactor. The reaction rate is strongly dependent on temperature and sodium hydroxide concentration. The variation trends of dissolution rate with time under different temperatures and concentrations are similar. The value of dissolution rate changes significantly in different temperature ranges. With $60 \mathrm{wt} . \%$ sodium hydroxide solution and reaction time of $6 \mathrm{~h}$, the dissolution rate increases $12.5 \%$ and $46 \%$, respectively, when the temperature increases from 180 to $200{ }^{\circ} \mathrm{C}$ and from 200 to $220^{\circ} \mathrm{C}$. The dissolution rate increases with increasing temperature and sodium hydroxide concentration. Higher temperatures and solution concentration are needed for the purpose of improving the efficiency of removing alumina cores.

(2) The fractal kinetic model was developed by assuming that nonporous particles shrank over time. The activation energy decreases with increasing initial solution concentration, and the values are $66.48 \mathrm{KJ} \cdot \mathrm{mol}^{-1}, 52.79 \mathrm{KJ} \cdot \mathrm{mol}^{-1}$ and $51.38 \mathrm{KJ} \cdot \mathrm{mol}^{-1}$ with sodium hydroxide concentrations of $50 \mathrm{wt} . \%, 60 \mathrm{wt} . \%$ and $65 \mathrm{wt} . \%$, respectively.

\section{References}

[1] Petot-Ervas G, Saadi B, Petot C, et al. Transport properties of titanium-doped a-alumina: experimental results. Journal of the European Ceramic Society, 1997, 17(7): 943-950.

[2] Bai S N, Tseng T Y. Effect of alumina adoping on structural, electrical, and optical properties of sputtered $\mathrm{ZnO}$ thin films. Thin Solid Films, 2006, 515(3): 872-875.

[3] Graham L D, Capek M. Method and apparatus for removing core material. US. Patent No. 8091610. Washington, D.C.: U.S. Patent and Trademark Office, 2012.

[4] Sangeeta D. Method of dissolving or leaching ceramic cores in airfoils. US. Patent No. 5779809. Washington, D.C.: U.S. Patent and Trademark Office, 1998.

[5] Borom M P. Method for removing a magnesia doped alumina core material. US. Patent No. 4073662. Washington, D.C.: U.S. Patent and Trademark Office, 1978.

[6] Yan X. Hydrometallurgical new technology and equipment selection Application Manual. Beijing, China: Metallurgical Industry Press, 2006: 46-70. (In Chinese).

[7] Pereira J A M, Schwaab M, Dell O E. The kinetics of gibbsite dissolution in $\mathrm{NaOH}$. Hydrometallurgy, 2009, 96 (1-2): 6-13.

[8] Gu S Q, Cao R J, Chen X M. Steady state mathematical model of diasporic bauxite digestion. Steady state mathematical model of diasporic bauxite digestion. Nonferrous Metals, 1986, 38(2): 66-73. (In Chinese).

[9] Bao L, Zhang T A, Liu Y, et al. The most probable mechanism function and kinetic parameters of gibbsite dissolution in $\mathrm{NaOH}$. Chinese Journal of Chemical Engineering, 2010, 18(4): 630-634.

[10] Pokrovskii V A, Helgeson H C. Thermodynamic properties of aqueous species and solubilities of minerals at high pressure and temperatures: the system $\mathrm{Al}_{2} \mathrm{O}_{3}-\mathrm{H}_{2} \mathrm{O}-\mathrm{KOH}$. Chemical Geology, 1997, 137(3-4): 221-242.

[11] Wohlers A, Manning C E. Solubility of corundum in aqueous $\mathrm{KOH}$ solutions at $700{ }^{\circ} \mathrm{C}$ and $1 \mathrm{Gpa}$. Chemical Geology, 2009, 262(3-4): 310-317.

[12] Li C Q, Zhang P, Chen Q Y, et al. The digestion of synthetic gibbsite. Transactions of Nonferrous Metals Society of China, 1995, 5(3), 45-49.

[13] Packter A, Dhillon H S. Studies on recrystallized aluminium hydroxide precipitates: kinetics and mechanism of dissolution by sodium hydroxide solutions. Colloid and Polymer Science, 1974, 252: 249-256.

[14] Panias D, Asimidis P, Paspaliaris I. Solubility of boehmite in concentrated sodium hydroxide solutions: model development and assessment. Hydrometallurgy, 2001, 59(1): 15-29.

[15] Grénman H, Salmi T, Yu D, et al. Dissolution of boehmite in sodium hydroxide at ambient pressure: Kinetics and modeling, Hydrometallurgy, 2010, 102(1-4): 22-30.

[16] Xiao X G. Metallurgical Reaction Engineering. Shenyang, China: Northeastern University Press (in Chinese), 1989: 156-158.

[17] Haghtalab A, Papanglakis V G, Zhu X. The electrolyte NRTL model and speciation approach as applied to multicomponent aqueous solutions of $\mathrm{H}_{2} \mathrm{SO}_{4}, \mathrm{Fe}_{2}\left(\mathrm{SO}_{4}\right)_{3}, \mathrm{MgSO}_{4}$ and $\mathrm{Al}_{2}\left(\mathrm{SO}_{4}\right)_{3}$ at $230-270{ }^{\circ} \mathrm{C}$. Fluid Phase Equilibria, 2004, 220(2), 199-209.

[18] Thomsen K, Rasmussen P, Gani R. Correlation and prediction of thermal properties and phase behavior for a class of aqueous electrolyte systems. Chemical Engineering Science, 1996, 51(14), 3675-3683. 